\title{
Enhancement of out-of-plane mechanical properties of carbon fiber reinforced epoxy resin composite by incorporating the multi-walled carbon nanotubes
}

\author{
Seyed Ali Mirsalehi ${ }^{1} \cdot$ Amir Ali Youzbashi $^{1} \cdot$ Amjad Sazgar $^{2}$ (D)
}

Received: 16 March 2021 / Accepted: 3 May 2021

Published online: 13 May 2021

(C) The Author(s) 2021 OPEN

\begin{abstract}
In this study, epoxy hybrid nanocomposites reinforced by carbon fibers (CFs) were fabricated by a filament winding. To improve out-of-plane (transverse) mechanical properties, 0.5 and $1.0 \mathrm{Wt} . \%$ multi-walled carbon nanotubes (MWCNTs) were embedded into epoxy/CF composites. The MWCNTs were well dispersed into the epoxy resin without using any additives. The transverse mechanical properties of epoxy/MWCNT/CF hybrid nanocomposites were evaluated by the tensile test in the vertical direction to the $\mathrm{CFs}\left(90^{\circ}\right.$ tensile) and flexural tests. The fracture surfaces of composites were studied by scanning electron microscopy (SEM). The SEM observations showed that the bridging of the MWCNTs is one of the mechanisms of transverse mechanical properties enhancement in the epoxy/MWCNT/CF composites. The results of the $90^{\circ}$ tensile test proved that the tensile strength and elongation at break of nanocomposite with $1.0 \mathrm{Wt} . \% \mathrm{MWCNTs}$ improved up to $53 \%$ and $50 \%$ in comparison with epoxy/CF laminate composite, respectively. Furthermore, the flexural strength, secant modulus, and elongation of epoxy/1.0 Wt.\% MWCNT/CF hybrid nanocomposite increased 15\%, 7\%, and $9 \%$ compared to epoxy/CF laminate composite, respectively.
\end{abstract}

Keywords Epoxy $\cdot$ Carbon fibers $\cdot$ MWCNT $\cdot$ Nanocomposite $\cdot$ Transverse properties

\begin{tabular}{|c|c|c|c|}
\hline Abbreviations & & LVI & Low Velocity Impact \\
\hline CFs & Carbon Fibers & $90^{\circ}$ tensile test & Tensile test in the vertical direction to \\
\hline MWCNTs & Multi-Walled Carbon Nano-Tubes & & the CFs \\
\hline SEM & Scanning Electron Microscopy & $\mathrm{E}$ & Modulus \\
\hline $90^{\circ}$ UTS & $90^{\circ}$ Ultimate Tensile Strength & UTS & Ultimate Tensile Strength \\
\hline FRP & Fiber Reinforced Polymer & UD90 & Samples of $90^{\circ}$ tensile test \\
\hline GFs & Glass Fibers & SSA & Specific Surface Area \\
\hline CFRP & Carbon Fiber Reinforced Polymer & & \\
\hline DGEBA & DiGlycidyl Ether of Bisphenol A & \multirow{3}{*}{\multicolumn{2}{|c|}{1 Introduction }} \\
\hline CNTs & Carbon NanoTubes & & \\
\hline CNTBPs & Carbon NanoTube BuckyPapers & & \\
\hline RFI & Resin Film Infusion & \multirow{3}{*}{\multicolumn{2}{|c|}{$\begin{array}{l}\text { In fiber reinforced polymer (FRP) composites, the fiber with } \\
\text { excellent mechanical, physical, and thermal properties } \\
\text { such as CF, glass fiber (GF), and aramid fiber is dispersed }\end{array}$}} \\
\hline CAl & Compression-After-Impact & & \\
\hline DMA & Dynamic Mechanical Analysis & & \\
\hline
\end{tabular}

Amjad Sazgar, asazgar@aeoi.org.ir | ${ }^{1}$ Faculty of Semiconductors, Materials and Energy Research Center (MERC), 31787-316 Karaj, Iran. ${ }^{2}$ Nuclear Fuel Cycle Research School, Nuclear Science and Technology Research Institute (NSTRI), 11365-8486 Tehran, Iran.

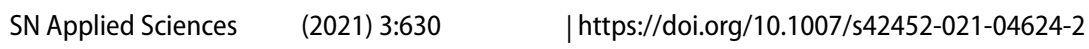


into the polymer matrix. These composites have unique properties (such as lightweight, high performance, higher stiffness, and so on) and are widely used in different industries [1-3]. Recently, researchers have been investigated the industrial functionalities of FRP composites. Aamir et al. [4] reviewed aerospace applications of carbon fiber reinforced polymer (CFRP) composites. Hassan et al. [5] focused on marine applications of epoxy/GF composite that Kevlar fiber stitched in the z-direction of samples.

Epoxies, as thermoset polymers, have been characterized by great chemical, thermal, and mechanical resistance, long dimensional stability, and good adhesiveness. These properties have made them be widely utilized in FRP composites as a matrix [6]. Diglycidyl ether of bisphenol $A(D G E B A)$ is a thermoset epoxy with great mechanical, dynamical, and thermal properties, chemical resistance, and good fiber impregnation characteristics in comparison with the other polymers which has been widely used in CFRP composites [7].

In recent years, CF reinforced epoxy resin composites have attracted much attention due to their excellent properties when compared to the polymer matrix alone or relative conventional composites [8]. The epoxy/CF composites possess excellent properties, such as high stiffness and strength, corrosion resistance, easy processing, and facile large-scale production, which have been widely utilized in aerospace and railway $[9,10]$. Great in-plane specific mechanical strength in the fiber direction also is important for CF-reinforced composites which facilitate carrying loads in the embedded CF direction. Although mechanical properties of composite laminates in the fiber direction are strong and these properties are insignificant in the vertical direction. Furthermore, the out-of-plane properties of epoxy/CF composites are matrix-dependent [11]. Therefore, out-of-plane properties are weaker than in-plane properties in CFRP due to the lower mechanical resistance of matrixes as compared to CFs [12]. This weakness may be problems that can cause matrix cracking and thereby ply delamination when out-of-plane loads apply [13].

The carbon nanotubes (CNTs) have been widely employed to augment properties of CFRP composites due to their great multi-functional properties, such as strong interfacial interactions and excellent stress transferring $[14,15]$. The in-plane and out-of-plane properties can be improved by embedding CFs and nano-fillers, respectively [9]. Cheng et al. [16] studied the effect of carbon nanotube buckypapers (CNTBP) on the flexural properties of laminated FRP and quoted that CNTBP increases flexural properties. Avil et al. [17] studied the effect of the CNTs on the damping behavior of epoxy and CFRP composite. Yourdkhani et al. [18] were manufactured CFRP composite by resin film infusion (RFI) process. They investigated the effect of the dispersion of CNTs on compression-after-impact (CAI) strength and electrical conductivity of samples. Han et al. [19] compared the effects of halloysite nanotubes, CNTs, and silicon carbide whiskers on the mechanical properties of epoxy/CF composites. Islam et al. [20] were added surface-modified MWCNTs and nanoclay to epoxy reinforced by CF composites. They investigated mechanical properties of composites using Dynamic Mechanical Analysis (DMA), Low Velocity Impact (LVI), and flexural tests [20]. In the literature, there is still a limited number of studies conducted for the epoxy matrix composites reinforced with CFs and MWCNTs which are evaluated the $90^{\circ}$ tensile test properties.

To improve mechanical properties, the appropriate dispersion of CNTs in hybrid nanocomposite matrices is a critical issue. The CNTs are prone to be easily agglomerated, due to the bearing strong Van der waals forces [21]. Some investigators have studied the methods for uniformly dispersing CNTs into FRP composites [13, 22-25]. Specific techniques have to be developed to grow CNTs on the surface of CFs [26]. The spray coating method was found to be effective in depositing CNTs onto the epoxy/ CF prepregs [27]. Islam et al. [20] also used a mechanical mixer, ultra-sonic, and three roll mixers to disperse embedded the MWCNTs into the epoxy matrix.

The objectives of this paper are (i) to well-dispersed MWCNTs into epoxy resin using the high-power probeultrasonic and mechanical mixer method without any solvent addition, (ii) to investigate the effectiveness of MWCNTs incorporation for transverse mechanical properties of epoxy/CF laminate composite, (iii) to compare the effects of various weight percent of MWCNTs on the transverse mechanical properties of the composites, (iv) to perform the tensile test in the vertical direction to the CFs $\left(90^{\circ}\right.$ tensile test) and three-point bending tests for evaluation of out-of-plane mechanical properties, and finally (v) to comprehensive microstructure characterization of composites.

\section{Materials and methods}

\subsection{Materials}

In this study, DGEBA type epoxy resin (2,2-Bis(4-glycidyloxyphenyl)propane Epoxide A) from MERCk (CAS Number: 1675-54-3), MWCNT (multiple rolled layers of graphene) from US Research Nanomaterials, Inc. (Code: US4306), hardener (methyl tetrahydrophtalic anhydride) from Chemwill (CAS Number:19438-64-3), accelerator (1-Methylimidazole) from MERCK (CAS Number: 616-477), and CF (hexagonal aromatic rings of carbon atoms) from CSTsales (UNSPSC code: $11,162,100$ ) were used as the primary materials. The epoxy resin system consisted of DGEBA, hardener, and accelerator. The resulting epoxy 
system is an anhydride and hot-cure polymer. This system showed high potential for manufacturing the composites with filament winding, pultrusion, and pressure molding methods. The ultimate tensile strength (UTS) and modulus (E) of CFs are 4.9 and $230 \mathrm{GPa}$, respectively [28]. In this study, CFs with sizing was purchased to enhance wettability and structural properties. The outer diameter of the un-functionalized MWCNTs is $10-20 \mathrm{~nm}$ (Fig. 1). The true density and purity of MWCNTs are $2.1 \mathrm{~g} / \mathrm{cm}^{3}$ and greater than $95 \%$, respectively. The theoretical UTS and E of CNTs are $130 \mathrm{GPa}$ and $1 \mathrm{TPa}$, respectively [29].

\subsection{Sample preparation and testing}

\subsubsection{Dispersion method and sample preparation}

Using ultrasonic and high-speed shearing is a simple method to improve the dispersion of nano-fillers in an epoxy resin matrix [30]. As can be seen in Fig. 2a, the MWCNTs were initially added to the hardener with relatively low viscosity $\left(50-100 \mathrm{mPa}\right.$ s) at $25^{\circ} \mathrm{C}$, which allows for ultra-sonicating CNTs without solvent. The MWCNTs were sonicated in the hardener by probe-ultrasonic for 30 min under $200 \mathrm{~W}$ power at room temperature. Then, the DGEBA epoxy resin was added to the ultra-sonicated hardener/MWCNT. To facilitate the appropriate mixing of hardener/MWCNT in the epoxy with high viscosity, a mechanical mixer was used at $1500 \mathrm{rpm}$ for $30 \mathrm{~min}$ at $75^{\circ} \mathrm{C}$. Next, the accelerator was added to the hardener/MWCNT/epoxy mixture. A mechanical mixer with $800 \mathrm{rpm}$ was used to stir

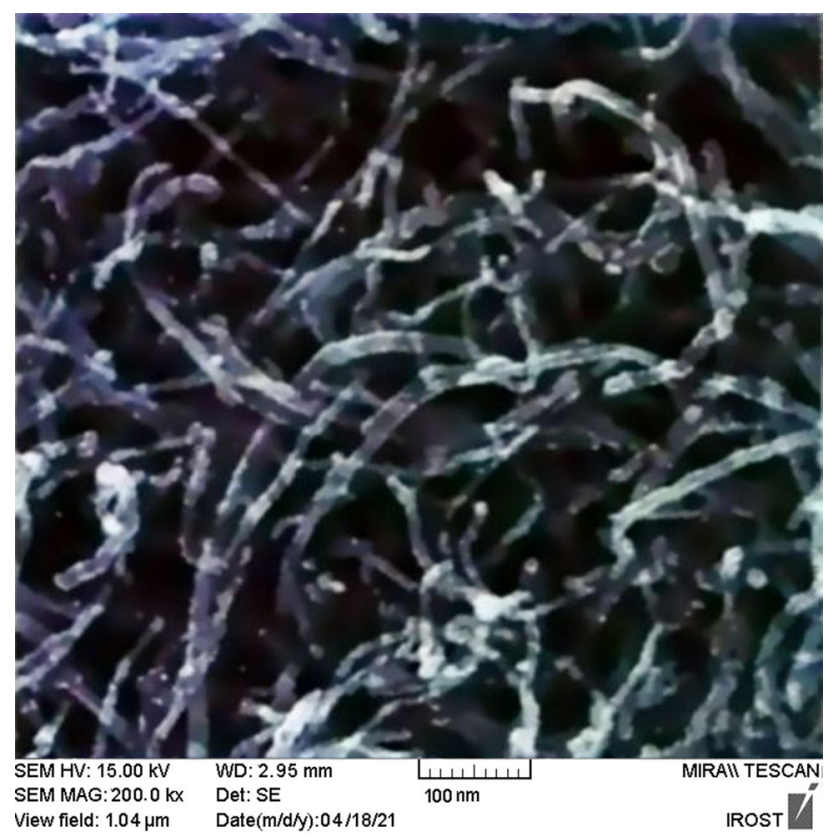

hardener/MWCNT/epoxy/accelerator mixture for $10 \mathrm{~min}$ at $40{ }^{\circ} \mathrm{C}$. Finally, the mixture was vacuumed to remove trapped air. The vacuum level was increased step by step up to $10^{-2}$ mbar. To prevent the epoxy from boiling, the vacuum pump was stopped before boiling began.

The DGEBA epoxy resin as a matrix was mixed with hardener and accelerator in the ratio of 100:70:2.5 Wt.\%, respectively. Components were thoroughly mixed to ensure homogeneity. The unidirectional composite laminates with $60 \mathrm{Wt} . \%$ CFs and 0, 0.5, and $1.0 \mathrm{Wt} . \%$ MWCNTs were fabricated by filament winding machine (Fig. 2b). Then, composites were cured at $2 \mathrm{~h} / 70^{\circ} \mathrm{C}+3 \mathrm{~h} / 130^{\circ} \mathrm{C}$.

\subsection{2 $90^{\circ}$ tensile test}

Samples of $90^{\circ}$ tensile test (UD90) with dimensions of $2.5 \times 25 \times 175 \mathrm{~mm}^{3}$ were cut by waterjet from a twelve-ply plate in the vertical direction to the CFs according to ASTM D 3039 [31]. To effectively apply force to the samples during the tensile test, $25 \times 25 \times 1.5 \mathrm{~mm}^{3}$ Aluminum tabs with $90^{\circ}$ bevel angle were bonded to the specimens (Fig. 3).

Tensile experiments of samples were performed by a universal testing machine at a cross-head speed of $2.0 \mathrm{~mm} / \mathrm{min}$ according to the standard ASTM D 3039 [31]. The transverse mechanical properties (i.e., $90^{\circ}$ UTS, E, and elongation at break) were evaluated. At least, five samples were tested for each composite to achieve reasonable results.

\subsubsection{Flexural test}

The flexural properties of epoxy/CF composites with and without MWCNTs were evaluated by a three-point bending test according to the ASTM D 790 [32]. The flexural strength, secant modulus, and elongation at break were measured by a three-point bending test. Samples were cut by waterjet from a twelve-ply plate (as shown in Fig. 3a) with dimensions of $2.5 \times 15 \times 250 \mathrm{~mm}^{3}$ in the parallel direction to the CFs. Figure 4 exhibits a schematic of the threepoint bending test and test sample. The loading nose and supports were designed by cylindrical surfaces. The radius of the loading nose and supports were chosen to avoid excessive indentation and stress concentration directly under the loading nose which causes unacceptable failure. To prevent contact of the sample with the sides of the nose, the arc of the loading nose in contact with the sample was sufficiently large. The epoxy/CF composite with a high-strength was designed to the span-to-depth ratio of 60:1 to occur failure in the outer surface of fibers. This span-to-depth ratio was caused to eliminate the shear effect.

Fig. 1 SEM image of MWCNTs 
Fig. 2 Schematic of (a) MWCNTs dispersion into epoxy resin and (b) filament winding process for fabricating composites

Probe-ultra sonicating of hardener/MWCNT for 30 min with200W@25 ${ }^{\circ} \mathrm{C}$

MWCNTs

(0.5 and $1.0 \mathrm{Wt} . \%$ of resin)
Hardener

(Viscosity@ $25^{\circ} \mathrm{C}=$ $50-100 \mathrm{mPa} \mathrm{s}$ )

\section{DGEBA epoxy (Viscosity@25 ${ }^{\circ} \mathrm{C}=$ $10000-12000 \mathrm{mPa} \mathrm{s}$ )}

add

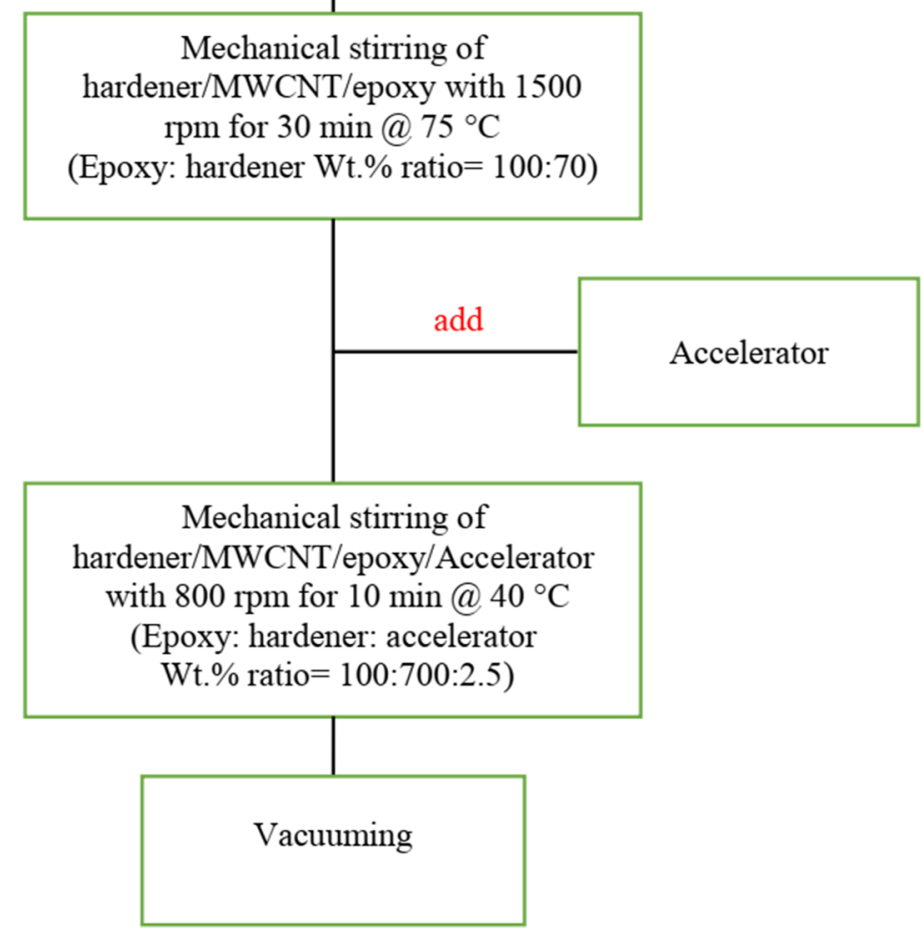

b

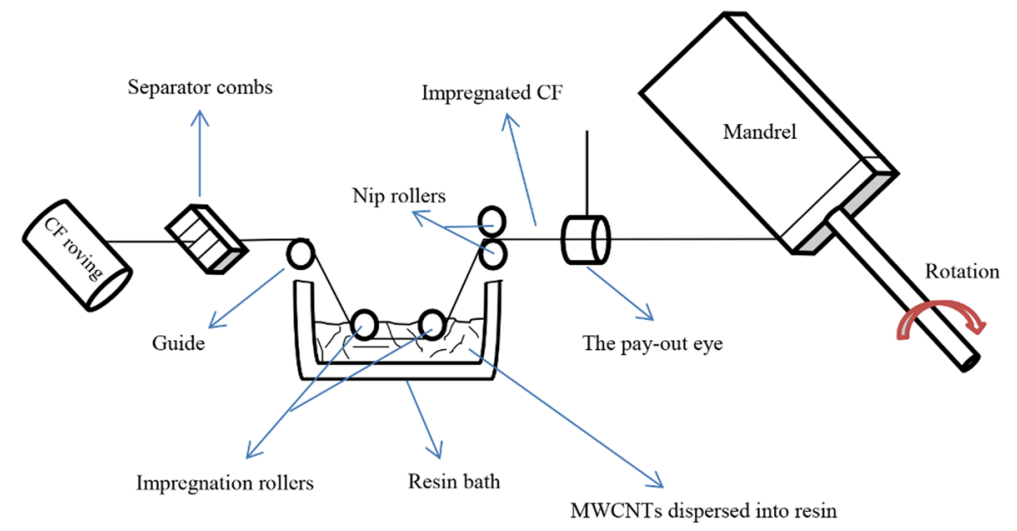

According to the ASTM D 790, the speed of the crosshead motion of the three-point bending test machine was $15.0 \mathrm{~mm} / \mathrm{min}$ can be calculated by Eq. 1:
$R=Z L^{2} / 6 d$

where $R(\mathrm{~mm} / \mathrm{min})$ is the rate of crosshead motion, $L(\mathrm{~mm})$ is the support span, $d(\mathrm{~mm})$ is the thickness of the sample, 
Fig. 3 The details of sample preparation for $90^{\circ}$ tensile test (a)Twelve-ply plate of composite, (b) schematic of UD90 sample with dimensions, and (c) UD90 tensile test specimen

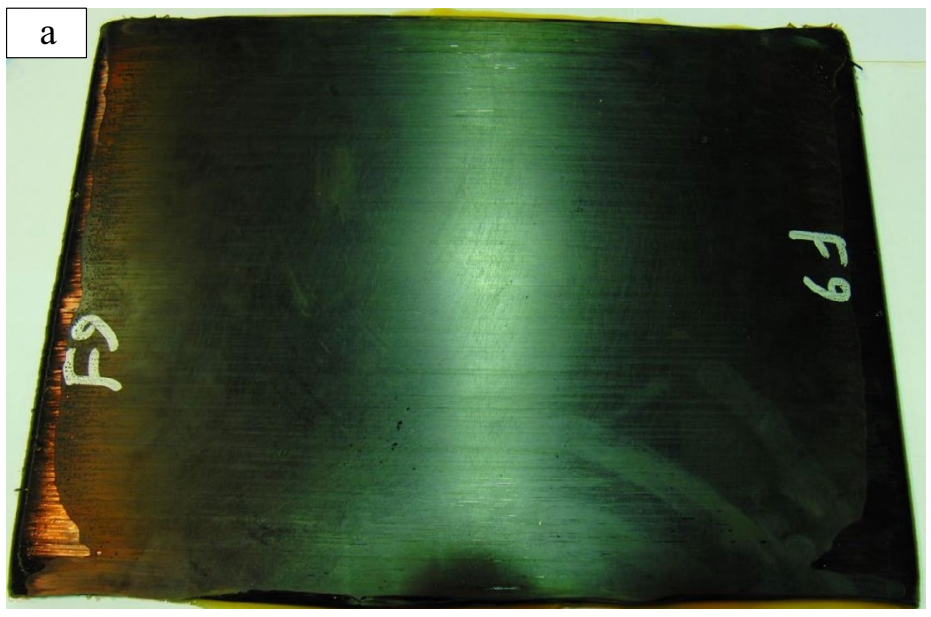

b
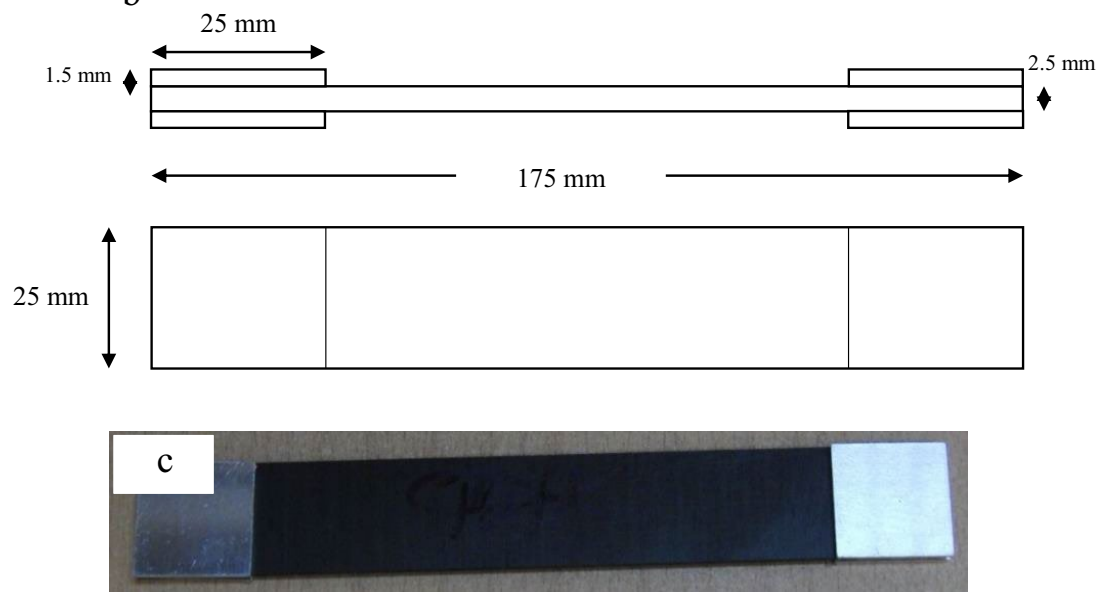

and $\mathrm{Z}\left(\mathrm{min}^{-1}\right)$ is the rate of straining of the outer fiber and shall be equal to $0.01 \mathrm{~min}^{-1}$.

The flexural stress of the sample which is loaded at the midpoint and supported at two points was calculated by using Eq. 2:

$\sigma_{f}=3 P L / 2 b d^{2}$

where $\sigma_{\mathrm{f}}(\mathrm{MPa}), \mathrm{P}(\mathrm{N})$, and $\mathrm{b}(\mathrm{mm})$ are the flexural stress, load, and width of the sample, respectively.

The flexural strain is the nominal fractional change in the length of an element of the outer surface of the sample at midspan, where the maximum strain occurs. It was calculated for any deflection by Eq. 3:

$\varepsilon_{f}=6 D d / L^{2}$

where $\varepsilon_{f}(\mathrm{~mm} / \mathrm{mm})$ is the strain in the outer surface and D $(\mathrm{mm})$ is the maximum deflection of the center of the test sample.

The slope of the straight line is the secant modulus when it joins the selected point and origin on the actual stress-strain curve. On the other hand, it is the ratio of stress to corresponding strain at any selected point on the stress-strain curve [32].

\section{Results}

\subsection{Microstructural study}

The CF-reinforced epoxy laminate nanocomposite delaminates when subject to transverse or compressive load confirming the nature of laminated structure [33]. To solve this problem, it is necessary to add the MWCNTs in epoxy/CF laminate composite. The dispersion of the MWCNTs in epoxy-based composite was studied in Fig. 5, using SEM.

Incorporating CNTs with high specific surface area (SSA) into the matrix increased the internal energy of the system. The Van der waals forces among CNTs cause nanotube-nanotube adhesion. To minimize the SSA and internal energy, CNTs form aggregates. Ten to hundreds of individual CNTs make these agglomerations that are difficult to separate [34]. Embedding a high percentage of the MWCNTs into the epoxy-based composite increases 
Fig. 4 (a) Schematic of the three-point bending test and (b) test sample
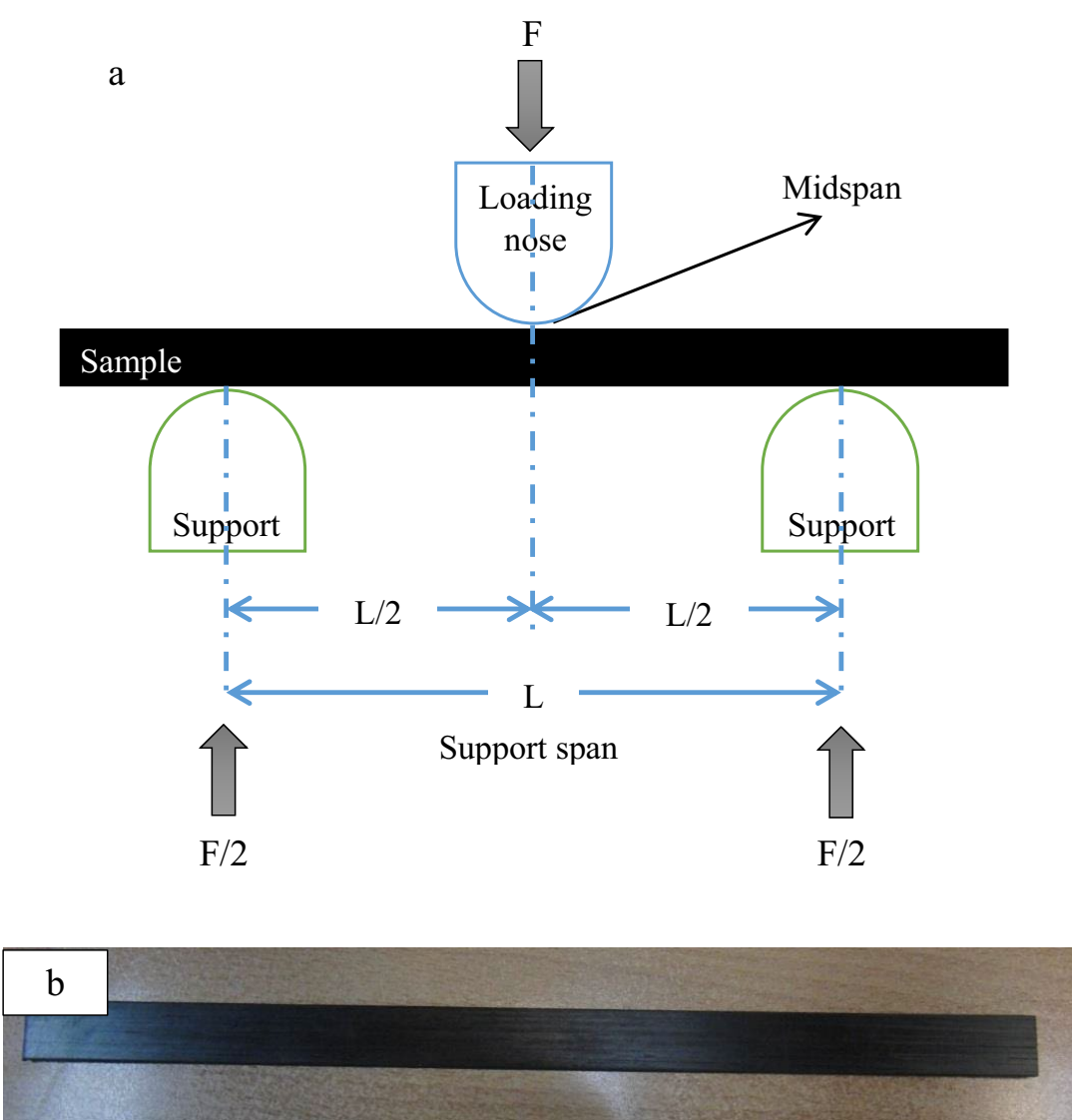

Fig. 5 The MWCNTs dispersion in nanocomposites (a) epoxy/0.5 Wt.\% MWCNT and (b) epoxy/1.0 Wt.\% MWCNT

the possibility of agglomeration. In nanocomposite with $1.0 \mathrm{Wt} . \%$ MWCNTs, the Van der walls forces among
MWCNTs are higher than the other specimens, so the possibility of aggregation is high. However, Fig. $5 \mathrm{~b}$ indicates 
a homogenous dispersion of MWCNTs throughout the epoxy resin in epoxy/1.0 Wt.\% MWCNT nanocomposite.

In this study, no additive was used for the MWCNTs distribution. The addition of additives may be helpful to achieve homogenous MWCNTs dispersion, but it may lead to the following problems:

I. An extra step in the preparation process to remove additives before curing.

II. Softening of the yielded composite due to low molecular weight [35].

III. The reagglomeration of the MWCNTs may occur during the removal process [24].

\subsection{Mechanical study}

The transverse mechanical properties of epoxy/MWCNT/ CF hybrid nanocomposites are evaluated by the $90^{\circ}$ tensile test. Typical tensile stress-strain curves of epoxy/MWCNT/ CF hybrid nanocomposites fabricated by $0,0.5$, and 1.0 Wt.\% MWCNTs in the vertical direction to the CFs are illustrated in Fig. 6. It is seen from Fig. 6 that the $90^{\circ}$ UTS and elongation increase as the MWCNTs loading increases. Also, the composites show pronounced linear behavior with large strains to failure.

The $90^{\circ}$ UTS, E, and elongation at break of epoxy/CF composite and epoxy/MWCNT/CF hybrid nanocomposites with 0.5 and $1.0 \mathrm{Wt} . \%$ MWCNTs are presented in Table 1.

As can be seen in Table 1, the $90^{\circ}$ UTS and elongation of composites continually enhance as the MWCNT content increases. It was seen that the epoxy/1.0 Wt.\% MWCNT/CF sample showed higher $90^{\circ}$ UTS and elongation than the other specimens. The $90^{\circ}$ UTS and elongation of epoxy/ CF composite were lower than the samples with MWCNTs. The average of the $90^{\circ}$ UTS, E, and elongation of the composite without MWCNTs are $27.5 \pm 1 \mathrm{MPa}, 6.72 \pm 0.17 \mathrm{GPa}$, and $0.34 \pm 0.01 \%$, respectively. The composite containing
$1.0 \mathrm{Wt} . \%$ MWCNTs shows a maximum of $90^{\circ} \mathrm{UTS}$ and elongation of $42 \pm 1.41 \mathrm{MPa}$ and $0.51 \pm 0.06 \%$, respectively which are approximately $53 \%$ and $50 \%$ greater than that of epoxy/CF composite. Furthermore, the $\mathrm{E}$ of epoxy/1.0 Wt.\% MWCNT/CF hybrid nanocomposite, which measures by the slope of the linear region in the stress-strain curve reaches approximately $6.8 \mathrm{GPa}$, which is about $2 \%$ more than that of the composite without the MWCNT incorporation. However, as shown in Table 1, composites had an E of the order of 6.45-7.17 GPa. In comparison with epoxy/CF composite, the E showed a very slight change. So, it should be noted that by adding $1.0 \mathrm{Wt} . \%$ MWCNTs the $90^{\circ}$ UTS and elongation increased but $\mathrm{E}$ is constant.

These results proved that the use of homogeneously dispersed MWCNTs improves the transverse mechanical properties of the fabricated composite as it could provide more the MWCNTs surfaces available to interact with the surrounding epoxy and increasing the strength of the epoxy resin matrix.

The fracture surface of the epoxy/CF laminate composite and epoxy/MWCNT/CF hybrid nanocomposite after the $90^{\circ}$ tensile test showing the fracture regions are presented in Fig. 7. As shown in Fig. 7a, interfacial de-bonding in epoxy/CF composite observes with no epoxy adhere to embedded CFs. There is a poor connection between the epoxy and CFs resulting in weak interfacial bonding. In

Table 1 The transverse mechanical properties of samples

\begin{tabular}{lrrl}
\hline Sample & $90^{\circ}$ UTS (MPa) & E (GPa) & $\begin{array}{l}\text { Elongation } \\
\text { at break } \\
(\%)\end{array}$ \\
\hline Epoxy/CF & $27.5 \pm 1.0$ & $6.72 \pm 0.17$ & $0.34 \pm 0.01$ \\
$\begin{array}{l}\text { Epoxy/0.5 Wt.\% MWCNT/ } \\
\text { CF }\end{array}$ & $30.75 \pm 4.34$ & $6.45 \pm 0.83$ & $0.41 \pm 0.05$ \\
$\begin{array}{l}\text { Epoxy/1.0 Wt.\% MWCNT/ } \\
\text { CF }\end{array}$ & $42 \pm 1.41$ & $6.8 \pm 0.08$ & $0.51 \pm 0.06$ \\
\hline
\end{tabular}

Fig. 6 The $90^{\circ}$ tensile stressstrain curves of manufactured epoxy/MWCNT/CF hybrid nanocomposite with $0,0.5$, and $1.0 \mathrm{Wt} . \%$ MWCNTs

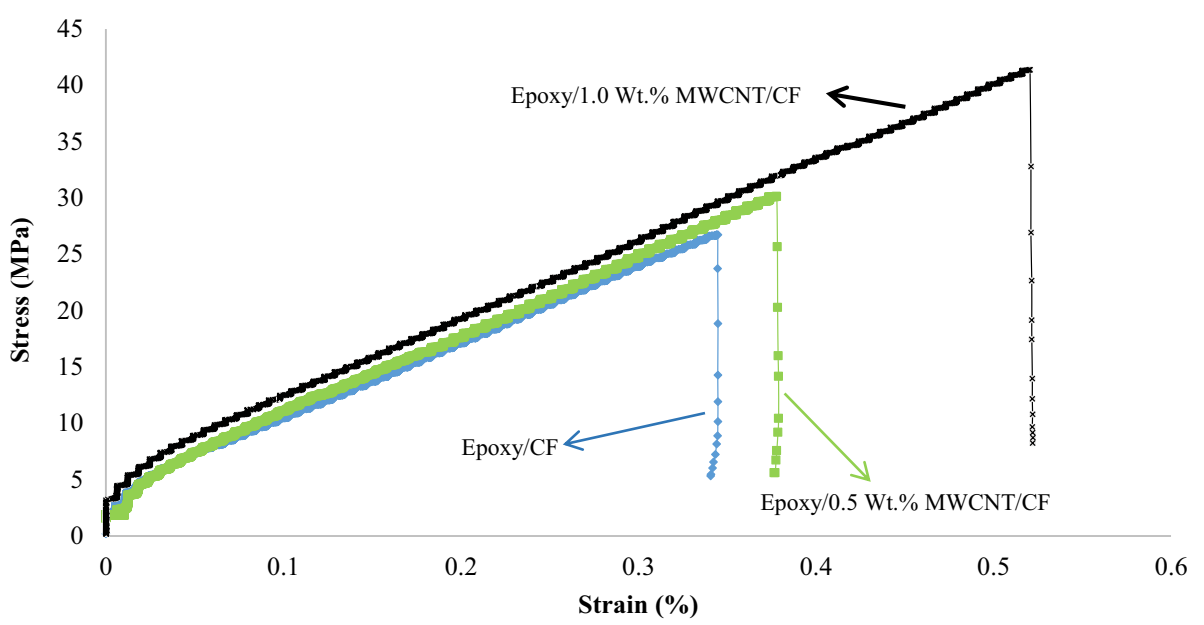

SN Applied Sciences 

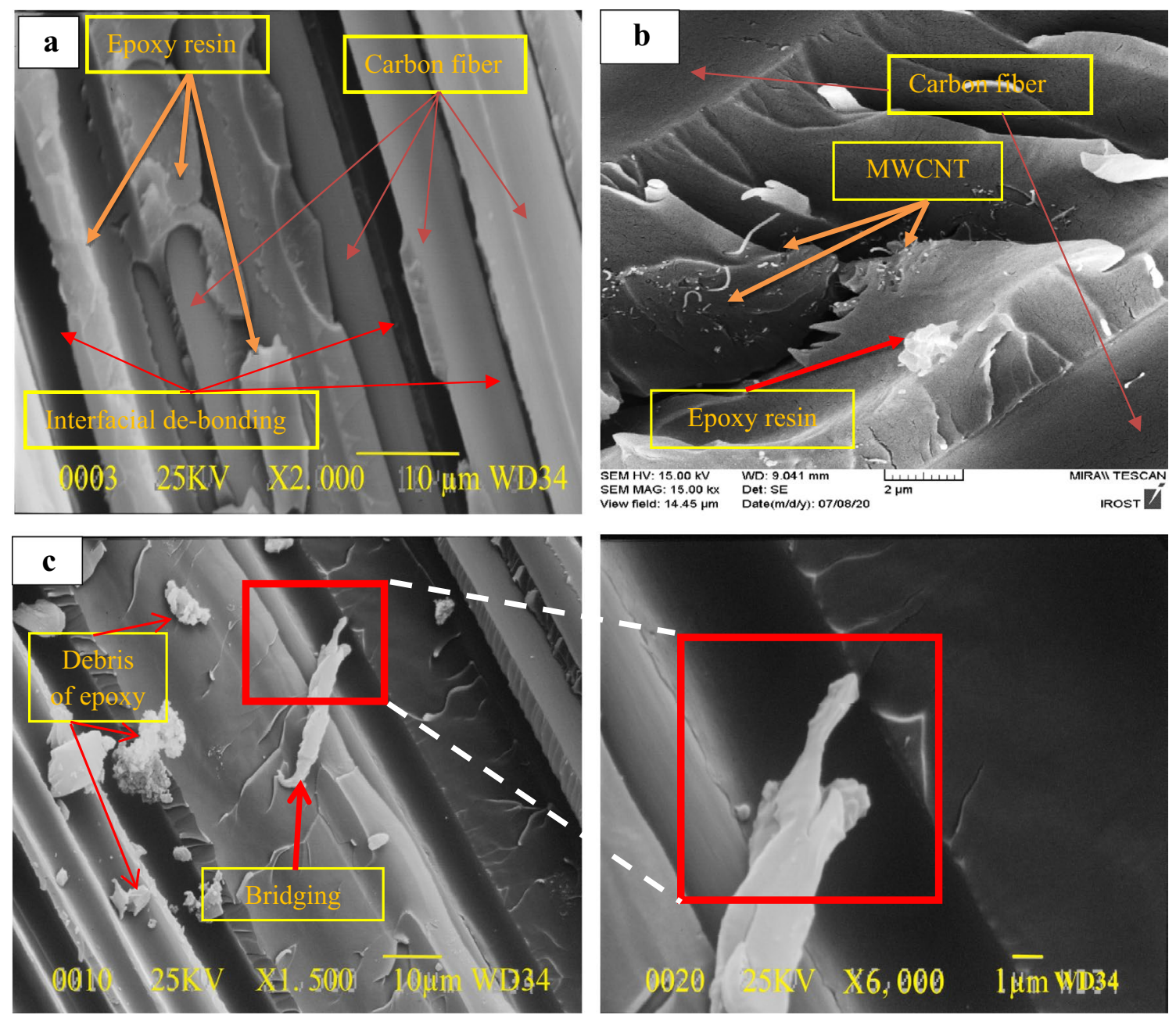

Fig. 7 SEM images of the fracture surfaces of (a) epoxy/CF laminate composite and (b, $\mathbf{c}$ ) epoxy/MWCNT/CF hybrid nanocomposite

contrast to epoxy/CF composite, by the MWCNTs incorporation, the fracture surface of nanocomposite changes that epoxy resin adheres to the CFs, indicating the strong interfacial bonding (Fig. 7b). Figure 7c shows the debris of epoxy and MWCNT. The indicated MWCNT made a bridge as an interlock between the CFs. As can be seen, the shape of bridged MWCNT (rope and cylindrical shape) and debris of epoxy (shapeless with a porous surface) is completely different due to epoxy resin was cured on the surface of MWCNTs during the preparation process of the nanocomposite. The bridged MWCNTs increased load transfer and interlaminar strength result in improving mechanical properties.

The flexural properties of epoxy/CF composites and epoxy/MWCNT/CF hybrid nanocomposites fabricated by 0.5 and $1.0 \mathrm{Wt}$.\% MWCNTs are measured by a three-point bending test. The flexural stress-strain curves of samples are shown in Fig. 8.
As can be observed in Fig. 8, flexural stress-strain curves of the composites illustrate the reinforcing effect of the MWCNTs and brittle fracture of the nanocomposites with almost no plastic deformation. The results of the threepoint bending test are presented in Table 2 .

According to Table 2, the flexural strength, secant modulus, and elongation at break of epoxy/CF composite are improved by the addition of the MWCNTs. As it is obvious in Table 2, the flexural strength values are $1374.02 \pm 7.45$ and $1251.26 \pm 3.8 \mathrm{MPa}$ for composites containing 1.0 and $0.5 \mathrm{Wt} . \%$ MWCNTs, respectively. These values are $15 \%$ and $5 \%$ higher than that of the flexural strength of epoxy/CF composite. The secant modulus and elongation of the nanocomposite with $1.0 \mathrm{Wt}$.\% MWCNTs are $7 \%$ and $9 \%$ more than that of the composite without the MWCNTs. The interaction between the epoxy polymer matrix with the MWCNTs in the interlaminar and intra-laminar region of the laminated composites resulted in proportional enhanced mechanical properties of the samples. Tariq 
Fig. 8 Flexural stress-strain curves of nanocomposites

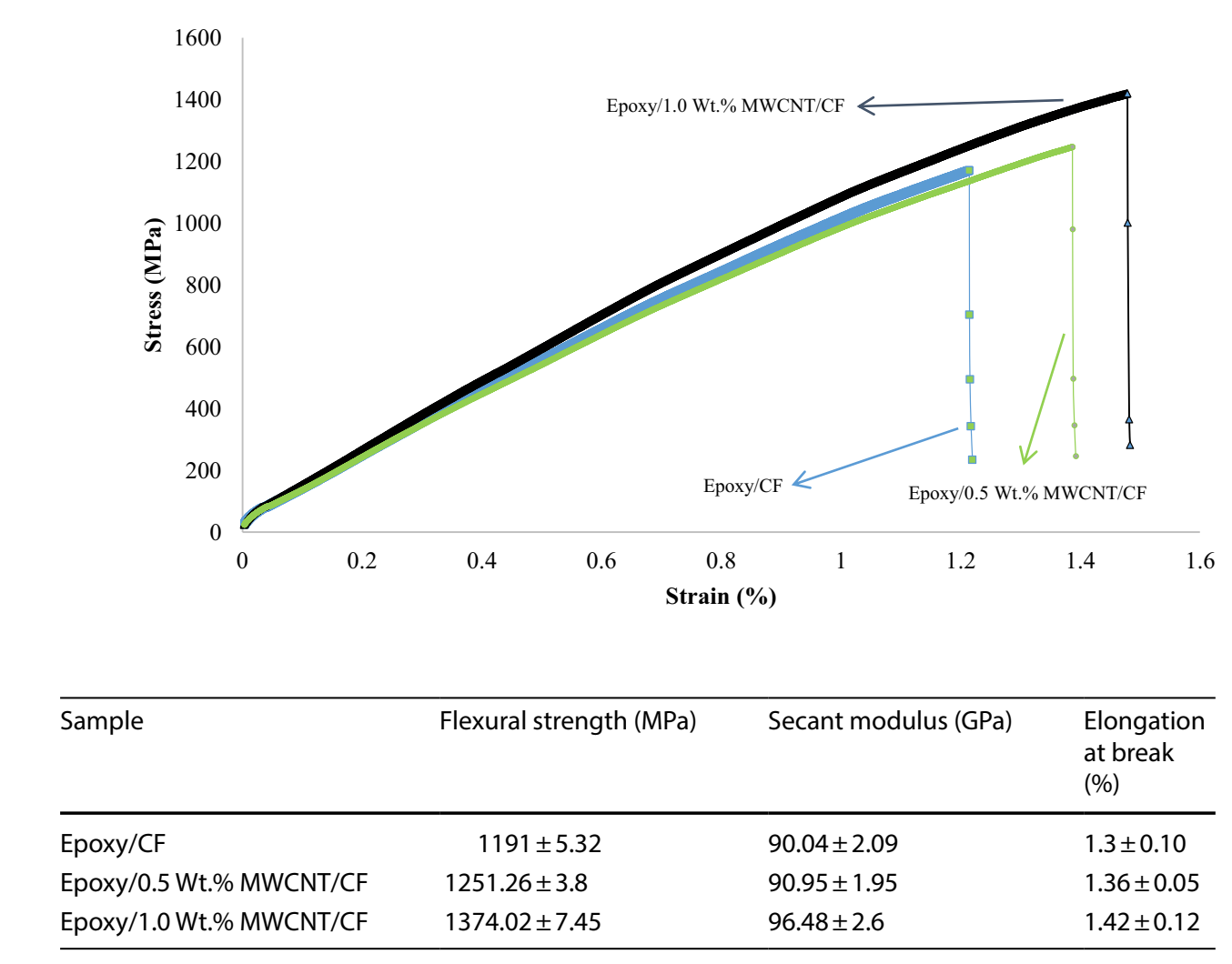

\begin{tabular}{lccc}
\hline Sample & Flexural strength (MPa) & Secant modulus (GPa) & $\begin{array}{l}\text { Elongation } \\
\text { at break } \\
(\%)\end{array}$ \\
\hline Epoxy/CF & $1191 \pm 5.32$ & $90.04 \pm 2.09$ & $1.3 \pm 0.10$ \\
Epoxy/0.5 Wt.\% MWCNT/CF & $1251.26 \pm 3.8$ & $90.95 \pm 1.95$ & $1.36 \pm 0.05$ \\
Epoxy/1.0 Wt.\% MWCNT/CF & $1374.02 \pm 7.45$ & $96.48 \pm 2.6$ & $1.42 \pm 0.12$ \\
\hline
\end{tabular}

Table 2 The flexural strength, secant modulus, and elongation at break of composites achieved from three-point bending test et al. [9] reported enhancement in flexural properties for epoxy/0.25 Wt.\% MWCNT/carbon fabric composite. Sharma et al. [36] stated that the maximum improvement by $25 \%$ in flexural strength was achieved by incorporating 0.5 Wt.\% amine-functionalized MWCNTs in CFRP composites.

Fracture surfaces of nanocomposites after the threepoint bending test were observed by SEM (Fig. 9).

Figure 9a exhibits the fracture surface of an epoxy/ CF laminate composite with low magnification, which showed a typical brittle fracture with island-like patterns. The pull-out of fiber, fiber breakage, and interfacial debonding was observed in the fracture surface of epoxy/ CF composite (Fig. 9b). As can be seen in Fig. 9c, well dispersion of the MWCNTs into the epoxy resin results in the enhancement of flexural strength. The MWCNTs enable to make a strong mechanical link between the fracture surfaces due to their excellent mechanical properties as well as large specific surface area.

The difference between elongations which are measured by the tensile and flexural tests might be due to the strain rate of the test. The speed of cross-head motion of the flexural test 6.5 times more than the tensile test. These speeds were chosen according to related standards.

The improvement of dispersion and interfacial bonding of the MWCNTs in the epoxy resin enhances an effective stress transfer between epoxy and CFs. Incorporating 1.0
Wt.\% MWCNTs compared to $0.5 \mathrm{Wt}$.\% MWCNTs provide higher SSA in epoxy/CF composite. So, there is a more desirable interface for stress transfer in epoxy/1.0 Wt.\% MWCNT/CF in comparison with epoxy/0.5 Wt.\% MWCNT/ CF hybrid nanocomposites.

The MWCNTs hold the epoxy resin matrix together by nano-stitches and enhance mechanical properties of the matrix, which lead to better transverse mechanical properties of epoxy/MWCNT/CF hybrid nanocomposite than that of epoxy/CF laminate composite. The composites containing 1.0 Wt.\% MWCNTs that are homogenously dispersed have two times more MWCNTs contents as epoxy/0.5 Wt.\% MWCNT/CF composites. Hence, the mechanical properties of the matrix of the hybrid nanocomposite were further improved by $1.0 \mathrm{Wt}$.\% MWCNTs.

The delamination and matrix cracking in the laminated composite may be due to the voids created in the interface of CF and the epoxy resin matrix. The MWCNTs improve interlaminar bonding between CF and epoxy and effective amount of voids reductions in the interface of reinforcement and matrix. Hence, an improving adhesion between CFs and epoxy plays an important role in stress transfer and causes the improvement of mechanical properties. The higher content of well-dispersed MWCNTs further enhanced interlaminar bonding and adhesion between CFs and epoxy. Therefore, interlaminar bonding and adhesion between CFs and matrix in epoxy/1.0 Wt.\% MWCNT/ 

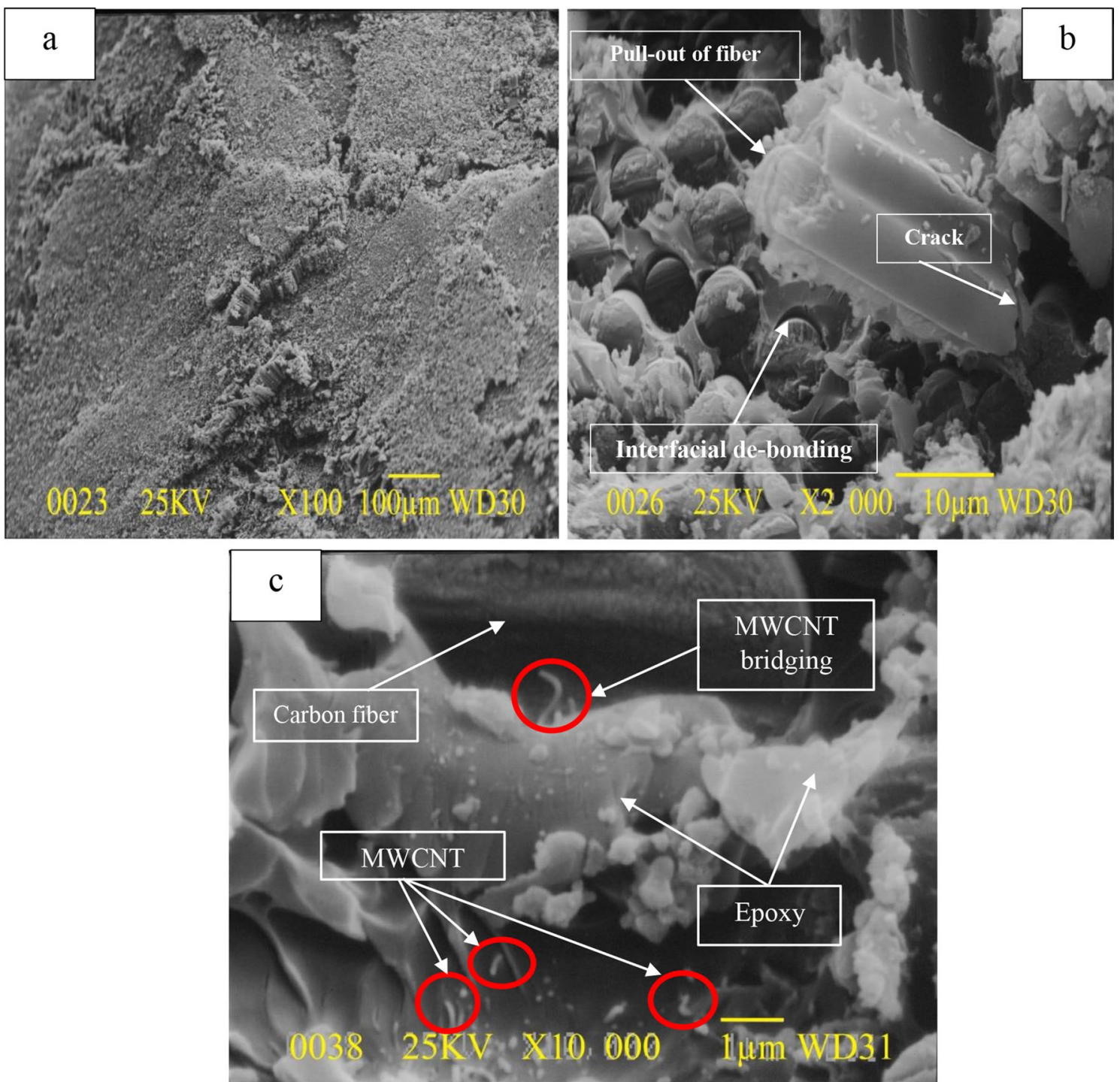

Fig. 9 SEM images of fracture surfaces of three-point bending samples (a, b) epoxy/CF composite and (c) epoxy/MWCNT/CF hybrid nanocomposites

CF composite is stronger than epoxy/0.5 Wt.\% MWCNT/CF hybrid nanocomposite.

\section{Conclusions}

The epoxy/CF laminate composite and epoxy/MWCNT/CF hybrid nanocomposites with 0.5 and $1.0 \mathrm{Wt} . \%$ MWCNTs were fabricated by a filament winding machine. The flexural and $90^{\circ}$ tensile properties of samples were evaluated by the three-point bending and $90^{\circ}$ tensile tests, respectively. The results show that the out-of-plane properties of epoxy/CF composite were improved by incorporating the $1.0 \mathrm{Wt} . \%$ MWCNTs. The following conclusions were drawn:
1. The MWCNTs were homogeneously dispersed into the epoxy resin matrix using a high-power probeultrasonic and mechanical mixer without using any additives.

2. The $90^{\circ}$ UTS and elongation at break of epoxy $/ 1.0 \mathrm{Wt} . \%$ MWCNT/CF hybrid nanocomposite were approximately $53 \%$ and $50 \%$ greater than that of epoxy/CF composite, respectively.

3. In comparison with epoxy/CF composite, the flexural strength, secant modulus, and elongation of epoxy/1.0 Wt.\% MWCNT/CF hybrid nanocomposite increased $15 \%, 7 \%$, and $9 \%$, respectively. 
Acknowledgements The authors wish to gratefully thank the support of the Iran Nanotechnology Initiative Council.

\section{Declarations}

Conflicts of interest The authors declare that they have no conflict of interest.

Open Access This article is licensed under a Creative Commons Attribution 4.0 International License, which permits use, sharing, adaptation, distribution and reproduction in any medium or format, as long as you give appropriate credit to the original author(s) and the source, provide a link to the Creative Commons licence, and indicate if changes were made. The images or other third party material in this article are included in the article's Creative Commons licence, unless indicated otherwise in a credit line to the material. If material is not included in the article's Creative Commons licence and your intended use is not permitted by statutory regulation or exceeds the permitted use, you will need to obtain permission directly from the copyright holder. To view a copy of this licence, visit http://creativecommons. org/licenses/by/4.0/.

\section{References}

1. Din IU et al (2020) Sequential damage study induced in fiber reinforced composites by shear and tensile stress using a newly developed Arcan fixture. J Market Res 9(6):13352-13364

2. Din IU et al (2020) Design of a new Arcan fixture for in-plane pure shear and combined normal/shear stress characterization of fiber reinforced polymer composites. Exp Tech 44(2):231-240

3. Ud Din I, Hao P, Aamir M, Franz G, Panier S (2019) FEM implementation of the coupled Elastoplastic/Damage model: failure prediction of Fiber reinforced polymers (FRPs) composites. J Solid Mech 11(4):842-853

4. Aamir M, Tolouei-Rad M, Giasin K, Nosrati A (2019) Recent advances in drilling of carbon fiber-reinforced polymers for aerospace applications: a review. The Int J Adv Manuf Technol 105(5):2289-2308

5. Hassan A, Khan R, Khan N, Aamir M, Pimenov DY, Giasin K (2021) Effect of seawater ageing on fracture toughness of stitched glass fiber/epoxy laminates for marine applications. J Mar Sci Eng 9(2):196

6. Backes EH, Passador FR, Leopold C, Fiedler B, Pessan LA (2018) Electrical, thermal and thermo-mechanical properties of epoxy/ multi-wall carbon nanotubes/mineral fillers nanocomposites. J Compos Mater 52(23):3209-3217

7. Kumar S, Krishnan S, Samal SK, Mohanty S, Nayak SK (2018) Toughening of petroleum based (DGEBA) epoxy resins with various renewable resources based flexible chains for high performance applications: a review. Ind Eng Chem Res 57(8):2711-2726

8. Zheng J, Liu P (2008) Elasto-plastic stress analysis and burst strength evaluation of Al-carbon fiber/epoxy composite cylindrical laminates. Comput Mater Sci 42(3):453-461

9. Tariq F, Shifa M, Baloch RA (2018) Mechanical and thermal properties of multi-scale carbon nanotubes-carbon fiber-epoxy composite. Arab J Sci Eng 43(11):5937-5948

10. Mohammed Z, Tcherbi-Narteh A, Jeelani S (2020) Effect of graphene nanoplatelets and montmorillonite nanoclay on mechanical and thermal properties of polymer nanocomposites and carbon fiber reinforced composites. SN Appl Sci 2(12):1959
11. Hossain M et al (2015) Enhanced mechanical properties of carbon fiber/epoxy composites by incorporating XD-grade carbon nanotube. J Compos Mater 49(18):2251-2263

12. Ulus H, Üstün T, Şahin ÖS, Karabulut SE, Eskizeybek V, Avcı A (2016) Low-velocity impact behavior of carbon fiber/epoxy multiscale hybrid nanocomposites reinforced with multiwalled carbon nanotubes and boron nitride nanoplates. J Compos Mater 50(6):761-770

13. Ou Y, González C, Vilatela JJ (2019) Interlaminar toughening in structural carbon fiber/epoxy composites interleaved with carbon nanotube veils. Compos Part A Appl Sci Manuf 124:105477

14. Sharma K, Kaushalyayan KS, Shukla M (2015) Pull-out simulations of interfacial properties of amine functionalized multiwalled carbon nanotube epoxy composites. Comput Mater Sci 99:232-241

15. Khadijeh Didehban IH, Barikani M, Sazgar A (2011) Investigation of mechanical and thermal properties of different modified MWNTs-epoxy nanocomposites, presented at the 7th international chemical engineering congress \& exihibition, Kish, Iran. Available: https://civilica.com/doc/340761

16. Cheng X, Liu L, Feng X, Shen L, Wu Z (2019) Low temperaturebased flexural properties of carbon fiber/epoxy composite laminates incorporated with carbon nanotube sheets. Macromol Mater Eng 304(10):1900247

17. Avil E, Kadioglu F, Kaynak C (2020) Contribution of carbon nanotubes to vibration damping behavior of epoxy and its carbon fiber composites. J Reinf Plast Compos 39(7-8):311-323

18. Yourdkhani M, Liu W, Baril-Gosselin S, Robitaille F, Hubert P (2018) Carbon nanotube-reinforced carbon fibre-epoxy composites manufactured by resin film infusion. Compos Sci Technol 166:169-175

19. Han S, Chung D (2013) Strengthening and stiffening carbon fiber epoxy composites by halloysite nanotubes, carbon nanotubes and silicon carbide whiskers. Appl Clay Sci 83:375-382

20. Islam ME, Mahdi TH, Hosur MV, Jeelani S (2015) Characterization of carbon fiber reinforced epoxy composites modified with nanoclay and carbon nanotubes. Procedia Eng 105:821-828

21. Samsur R, Rangari V, Jeelani S, Zhang L, Cheng Z (2013) Fabrication of carbon nanotubes grown woven carbon fiber/epoxy composites and their electrical and mechanical properties. J Appl Phys 113(21):214903

22. Tehrani M, Boroujeni A, Hartman T, Haugh T, Case S, Al-Haik M (2013) Mechanical characterization and impact damage assessment of a woven carbon fiber reinforced carbon nanotubeepoxy composite. Compos Sci Technol 75:42-48

23. Joshi SC, Dikshit V (2012) Enhancing interlaminar fracture characteristics of woven CFRP prepreg composites through CNT dispersion. J Compos Mater 46(6):665-675

24. An Q, Rider AN, Thostenson ET (2012) Electrophoretic deposition of carbon nanotubes onto carbon-fiber fabric for production of carbon/epoxy composites with improved mechanical properties. Carbon 50(11):4130-4143

25. Yengejeh SI, Kazemi SA, Öchsner A (2017) Carbon nanotubes as reinforcement in composites: a review of the analytical, numerical and experimental approaches. Comput Mater Sci 136:85-101

26. Wicks SS, de Villoria RG, Wardle BL (2010) Interlaminar and intralaminar reinforcement of composite laminates with aligned carbon nanotubes. Compos Sci Technol 70(1):20-28

27. Zhang H, Liu Y, Kuwata M, Bilotti E, Peijs T (2015) Improved fracture toughness and integrated damage sensing capability by spray coated CNTs on carbon fibre prepreg. Compos A Appl Sci Manuf 70:102-110

28. MInus M, Kumar S (2005) The processing, properties, and structure of carbon fibers. Jom 57(2):52-58 
29. Ruoff RS, Qian D, Liu WK (2003) Mechanical properties of carbon nanotubes: theoretical predictions and experimental measurements. C R Phys 4(9):993-1008

30. Zhou Y, Pervin F, Lewis L, Jeelani S (2008) Fabrication and characterization of carbon/epoxy composites mixed with multi-walled carbon nanotubes. Mater Sci Eng A 475(1):157-165

31. A. Standard (2008) ASTM D3039-Standard test method for tensile properties of polymer matrix composite materials

32. I. ASTM (2007) Standard test methods for flexural properties of unreinforced and reinforced plastics and electrical insulating materials, ASTM D790-07

33. Sun $Q$ et al (2019) Failure mechanisms of cross-ply carbon fiber reinforced polymer laminates under longitudinal compression with experimental and computational analyses. Compos B Eng 167:147-160

34. Gojny FH, Wichmann MH, Fiedler B, Schulte K (2005) Influence of different carbon nanotubes on the mechanical properties of epoxy matrix composites-a comparative study. Compos Sci Technol 65(15-16):2300-2313

35. Frømyr TR, Hansen FK, Olsen T (2012) The optimum dispersion of carbon nanotubes for epoxy nanocomposites: evolution of the particle size distribution by ultrasonic treatment. J Nanotechnol 2012:1-14

36. Sharma K, Shukla M (2014) Three-phase carbon fiber amine functionalized carbon nanotubes epoxy composite: processing, characterisation, and multiscale modelling. J Nanomater 2014:1-10

Publisher's Note Springer Nature remains neutral with regard to jurisdictional claims in published maps and institutional affiliations. 